\title{
Food reinforcement versus social reinforcement in timber wolf pups
}

\author{
MARTHA G. FRANK and HARRY FRANK \\ University of Michigan-Flint, Flint, Michigan
}

\begin{abstract}
Completion times for food-reinforced trials and socially reinforced trials were recorded for problem-solving tasks performed by 4 Eastern timber wolf pups (Canis lupus lycaon) at 6 and at 13 weeks of age. All subjects posted shorter times for socially reinforced trials on both tasks. Results are discussed in terms of species-specific constraints on learning.
\end{abstract}

Shettleworth (1972) pointed out that "general" laws of learning sought by traditional comparative psychologists have been derived almost entirely from the performance of rats, pigeons, and monkeys using food, water, and escape from electric shock as reinforcers. Even though Garcia and Koelling's (1966) discovery of speciesspecific constraints on learning has stimulated considerable research in the last two decades, Shettleworth's claim (p. 11) that there is little experimental data on the relative incentive value of different reinforcers remains largely true for wild species.

In this connection, a number of the experiments in our recently reported (Frank \& Frank, 1986) comparison of training-task and problem-solving performance in wolves (Canis lupus) and dogs (Canis familiaris) employed tasks devised for domestic dog pups by Scott and Fuller (1965). In two of these we felt it advisable to alternate the administration of social reinforcement with food reinforcement instead of administering food and social reinforcement jointly on every trial, as described by Scott and Fuller. This methodological departure quite incidentally yielded the sort of within-species comparison of reinforcers called for by Shettleworth (1972).

\section{METHOD}

The subjects in these experiments were 4 Eastern timber wolves (C. lupus lycaon), 1 male and 1 female from each of two litters, acquired at 11 days of age $( \pm 24 \mathrm{~h})$ from the Carlos Avery Game Park (Forest Lake, MN) and fostered on a mature, maiden wolf approximately 67 days after ovulation. Complete details of the subjects' rearing regimen were reported by Frank, Hasselbach, and Littleton (1986).

\section{Procedure}

Testing was conducted in an unroofed $9.75 \times 9.75 \mathrm{~m}$ arena constructed of unfinished plywood and situated in the 0.2-ha compound that the subjects shared with the foster mother wolf, an adult male Malamute, and an adult male wolf-Malamute hybrid.

Barrier test. The barrier test (Frank \& Frank, 1982; 1986, pp. 155-156) is an adaptation of Köhler's (1925/1927) detour test, which Scott and Fuller (1965, pp. 226-229) modified for use with 6-weekold puppies. Testing began on the Monday nearest the pups' 6-week birthday. After 2 days of habituation to the arena, each subject was placed

\footnotetext{
Address correspondence to Harry Frank, Department of Psychology, University of Michigan-Flint, Flint, MI 48502-2186.
}

Table 1

Order of Administration of Food (F) and Social (S) Reinforcements on Barrier Test

\begin{tabular}{|c|c|c|c|c|c|c|}
\hline \multirow[b]{2}{*}{ Subject } & \multicolumn{2}{|c|}{$\begin{array}{c}\text { Day } 1 \\
\text { Short Barrier }\end{array}$} & \multicolumn{2}{|c|}{$\begin{array}{c}\text { Day } 2 \\
\text { Long Barrier }\end{array}$} & \multicolumn{2}{|c|}{$\begin{array}{c}\text { Day } 3 \\
\text { U-Barrier }\end{array}$} \\
\hline & T1 & $\mathrm{T} 2$ & T1 & $\mathrm{T} 2$ & T1 & $\mathrm{T} 2$ \\
\hline 1 & $\mathbf{F}$ & $\mathbf{S}$ & $S$ & $\mathbf{F}$ & $\mathbf{F}$ & $\mathbf{S}$ \\
\hline 2 & $\mathbf{F}$ & $S$ & $\mathbf{S}$ & $\mathbf{F}$ & $\mathbf{F}$ & $\mathbf{S}$ \\
\hline 3 & $\mathbf{S}$ & F & $\mathbf{F}$ & $\mathbf{S}$ & S & $\mathbf{F}$ \\
\hline 4 & $\mathbf{S}$ & $\mathbf{F}$ & $\mathbf{F}$ & $\mathbf{S}$ & $\mathbf{S}$ & $\mathbf{F}$ \\
\hline
\end{tabular}

Note - T1 $=$ Trial 1. T2 $=$ Trial 2.

on one side of a 1.2-m-high plywood barrier with a 45-cm-wide wiremesh window through which the subject could see but not reach a reward object, and the subject therefore had to discover that the goal could be reached only by an indirect route. Three barrier configurations were used: Day 1-short barrier (2.4 m wide), Day 2-long barrier (7.3 m wide), Day 3-U-barrier (4.9 $2.4 \times 4.9 \mathrm{~m}$ open-ended rectangle with the mesh window at the closed, 2.4-m, end). On each day of testing, the subjects were administered two trials, one of which was reinforced with food and one of which was reinforced by a minute or so of interaction with an adult Malamute whom the pups were always eager to greet. Reinforcement schedules are given in Table 1.

Maze test. The maze test (Frank \& Frank, 1986, pp. 158-159) was administered to the same 4 wolf pups after 2 days of habituation beginning on the Monday nearest their 13-week birthday. Each subject received 10 consecutive daily trials in a six-unit $T$-maze of the same design as (but one-third larger than) the apparatus described by Scott and Fuller (1965, pp. 232-238). Testing was conducted $12 \mathrm{~h}$ after feeding on Days 1-5 and $18 \mathrm{~h}$ after feeding on Days 6-10. All subjects were carried from the home barn directly to the goal area of the maze and permitted to inspect the reward object before being carried to the startbox. Two of the pups were administered the predominantly right-turn pattern (RLLRRR) illustrated in Figure 1, and the other 2 were administered the reverse pattern (LRRLLL), achieved by moving each T-unit from one side of its gate to the other. Food reinforcement and social reinforcement (as described in the barrier test above) were administered on alternate days, and the order of presentation was counterbalanced across litters and across turn patterns, as shown in Table 2.

\section{RESULTS}

The dependent variable for both tasks, as discussed in Frank and Frank (1986), was number of errors (stops and changes in direction). The time required to reach the goal on each trial was also recorded, but was not reported because time "is generally assumed to tap motivational strength in addition to problem-solving ability" (Frank 


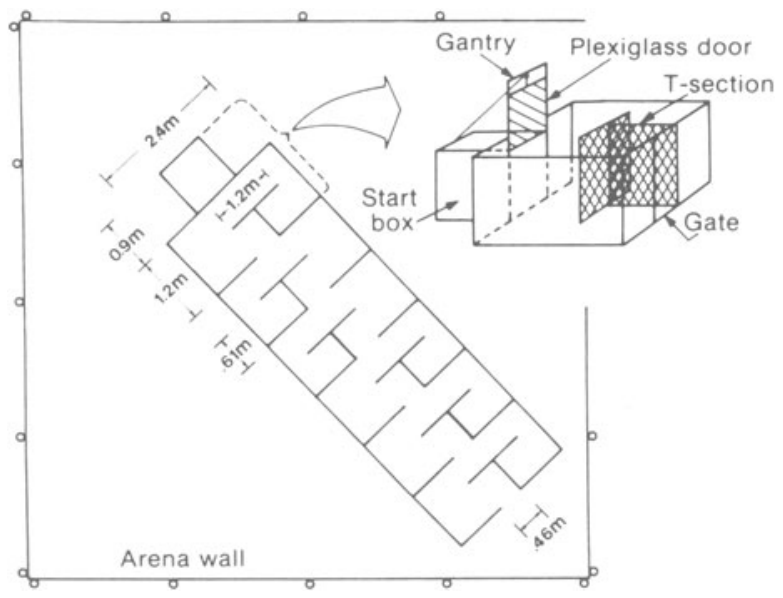

Figure 1. Schematic diagram of six-unit T-maze in right-turn pattern. Inset shows startbox and first unit of maze.

\& Frank, 1982, p. 97). In the analyses reported below, each subject's total time for socially reinforced trials is subtracted from his/her total time for food-reinforced trials. Positive differences are interpreted as indicating preference for social reinforcement and negative differences as indicating preference for food reinforcement.

Barrier test. Time totals for socially reinforced trials were less than time totals for food-reinforced trials for all 4 pups. By the criteria defined above, the proportion of subjects preferring social reinforcement was therefore 1.00 , and the proportion preferring food reinforcement was 0.00 . These values were submitted to a binomial test

Table 2

Order of Administration of Food (F) and Social (S) Reinforcement $\times$ Litter $\times$ Turn Pattern on Maze Test

\begin{tabular}{|c|c|c|c|c|c|c|c|c|c|c|c|}
\hline \multirow[b]{2}{*}{ Subject } & \multirow[b]{2}{*}{ Maze Pattern } & \multicolumn{10}{|c|}{ Day } \\
\hline & & 1 & 2 & 3 & 4 & 5 & 6 & 7 & 8 & 9 & 10 \\
\hline \multicolumn{12}{|c|}{ Litter 1} \\
\hline 1 & RLLRRR & F & $\mathbf{S}$ & $\mathbf{F}$ & $S$ & $\mathbf{F}$ & $S$ & $\mathbf{F}$ & $\mathbf{S}$ & $\mathbf{F}$ & $\mathbf{S}$ \\
\hline 3 & LRRLLL & $S$ & $\mathbf{F}$ & $\mathbf{S}$ & F & $\mathbf{S}$ & $\mathbf{F}$ & $\mathbf{S}$ & $\mathbf{F}$ & $\mathbf{S}$ & $\mathbf{F}$ \\
\hline \multicolumn{12}{|c|}{ Litter 2} \\
\hline 2 & RLLRRR & $\mathbf{S}$ & $\mathbf{F}$ & $S$ & F & $\mathbf{S}$ & $\mathbf{F}$ & S & $\mathbf{F}$ & $\mathbf{S}$ & $\mathbf{F}$ \\
\hline 4 & LRRLLL & $\mathbf{F}$ & $\mathbf{S}$ & $\mathrm{F}$ & S & $\mathbf{F}$ & $\mathbf{S}$ & $\mathbf{F}$ & $\mathbf{S}$ & $\mathbf{F}$ & $\mathbf{S}$ \\
\hline
\end{tabular}

against $\mathrm{H}_{0}: p=.50$. For $N=4$, the significance probability of our results is .0625 .

Maze test. The mean difference between subjects' time totaled over food-reinforced trials and time totaled over socially reinforced trials was computed to test the hypothesis $\mu_{d}=0$. On the average, the subjects required $163.5 \mathrm{sec}$ more to complete their five food-reinforced trials than to complete their five socially reinforced trials. With $S D=$ 68.5 , Student's $t=4.14(.01<p<.025, d f=3)$, and the test hypothesis is rejected.

\section{DISCUSSION}

Since the latent learning studies of the 1930s, psychologists have generally acknowledged that performance is a product of both acquisition and motivational incentive. Because both of our experiments used subjects as their own controls (and because acquisition as measured by number of errors was not significantly different for the two reinforcers in either experiment), our data suggest that social interaction with a congenor may have more incentive value for wolf pups than does food, at least up to $18 \mathrm{~h}$ of food deprivation. This finding is easily understood in terms of the wolf's gregarious nature and the feast-or-famine conditions under which it evolved. More important, as an increasing variety of nontraditional species comes into the purview of experimental animal learning, our results underscore the caveat that an appreciation of motivational differences among species is essential to the understanding of comparative animal performance.

\section{REFERENCES}

Frank, H., \& Frank, M. G. (1982). Comparison of problem-solving performance in six-week-old wolves and dogs. Animal Behaviour, 30, 95-98.

Frank, H., \& Frank, M. G. (1986). The University of Michigan canine information-processing project (1979-1981). In H. Frank (Ed.), Man and wolf: Advances, issues, and problems in captive wolf research (pp. 143-167). Dordrecht, The Netherlands: Junk.

Frank, H., Hasselbach, L. M., \& Littleton, D. M. (1986). Socialized vs. unsocialized wolves (Canis lupus) in experimental research. In M. W. Fox \& L. D. Mickley (Eds.), Advances in animal welfare science 1986/1987 (pp. 33-49). Washington DC: Humane Society of the United States.

Garcia, J., Koelling, R. A. (1966). Relation of cue to consequence in avoidance learning. Psychonomic Science, 4, 123-124.

KöHLER, W. (1927). The mentality of apes (2nd ed.). (E. Winter, Trans.). London: Routledge \& Kegan-Paul. (Original work published 1925)

SCOTT, J. P., \& FULLER, J. L. (1965). Genetics and the social behavior of the dog. Chicago: University of Chicago Press.

ShetTleworth, S. J. (1972). Constraints on learning. Advances in the study of behavior, 4, 1-62. 